\section{Astrology and cosmobiology}

SIR - Reviewing our book The Gemini Syndrome: $A$ Scientific Evaluation of Astrology (Nature, 15 November, p.219), H.J. Eysenck takes us to task for having "scandalously neglected" the work of the Gauquelins. Consequently, in our overall rejection of astrology, we are accused of carelessly discarding the baby with the bath water.

We agree with Eysenck regarding the attention deserved by the Gauquelins' research. We recognize that it should be included in more detail with our treatment of astrology, though Gauquelin considers his work to be "cosmobiology" not astrology. The paperback edition of the book adds only a few pages of new material to the original version written in 1977-78, and we regret we could do little more than mention a few highlights and provide pointers to the recent literature.

On the other hand, we admit to a rather different perception from Eysenck's of the



value of astrology and his words of review appear to reveal a positive view rather than an objective one. To us, the Gauquelin correlations make no physical sense and are inconsistent with the body of natural empirical evidence. The correlations are weak, and it is not clear that they could not be spurious. In any case, the implication of a causal relationship is not justified on purely statistical grounds. There seems not a hint of a reasonable explanation for them. The successful replications are essentially only those by Gauquelin; Eysenck omits reference to the several careful studies that failed to confirm the effect.

The Gemini Syndrome was the first such book written by scientists to take a detailed look at the evidence rather than simply to declare astrology intuitively invalid. For our single sin of under-emphasis, our reviewer finds the entire book an unacceptable scientific evaluation of astrology. We have gained some understanding of how it feels to be the aforementioned baby.

Eysenck refers to the work of the Gauquelins as a "nugget of gold" amidst the rubbish of evidential support for astrology. In fact it seems the scientific assay is not yet complete; we will be very surprised if the golden nugget does not turn out to be iron pyrite.

PHILIP A. IANNA
ROGER B. CULVER
Leander McCormick Observatory
of the University of Virginia,
Department of Astronomy,
Box 3818, University Station,
Charlottesville,
Virginia 22903-0818, USA

SIR - It is surprising to see Nature including book reviews ${ }^{1}$ that endorse superstition and pseudo-science. Eysenck is well known for his readiness to support controversial theories before there is any reliable evidence. An example is his support for "PSI" and parapsychology 2. It is interesting that Eysenck is often quoted by the tobacco industry on his critique of research correlating smoking with cancer.

Eysenck bases his positive assessment of astrology, or "cosmobiology" as he calls it, solely on the work of Françoise and Michel Gauquelin. He does not mention negative results obtained by others nor does he question the significance of the results.

The Gauquelins divide the sky into twelve sectors, the first beginning just over the eastern horizon. One of the claims mentioned by Eysenck is that the planet Mars appears in the sectors 1 and 4 at the birth of sports champions more often than for others ( 22 per cent instead of the expected 17 per cent). An attempt to replicate the experiment failed to yield positive results (13.5 per cent instead of 17 per cent) ${ }^{3}$. The results regained their significance only after the Gauquelins discarded a major portion of the data on the grounds that those came from "lesser sportsmen". This raises the question as to whether the studies previously conducted by the Gauquelins were not similarly biased by post hoc selections.

Eysenck also fails to mention that the Belgian study referred to ${ }^{1}$ had some major deficiencies. The sample size was small (535) and, more important, the sectors 9 and 10 appeared more often that the favoured sector 4 . In addition, the Gauquelins were involved in this study as well, thus contradicting Eysenck's claim of independence.

There is considerable doubt as to whether the work of Michel and Francoise Gauquelin is to be taken seriously in connection with astrology. On the contrary, there is every reason for responsible people to warn the public against being deceived by old-fashioned and modern astrologers. The book reviewed and the 186 signatories of the statement against astrology deserve our unrestrained support.

Ringstrasse 102,

AMARDEO SARMA

\section{D-6101 Rossdorf 1, FRG}

1. Eysenck, H.J. Nature, 312, 219-220 (1984)

2. Eysenck, H.J. P.M. Magazin, December 1984, 38-46.

3. Kurtz, P., Zelen, M. \& Abell, G. Skeptical Inquirer, IV(2), 19-26.

Gauquelin, M. \& Gauquelin, F. Skeptical Inquirer, IV(2) $31-43$

\section{Fever in autistics}

SIR - Bryant's recent review ${ }^{1}$ of a book by Tinbergen and Tinbergen ${ }^{2}$ was a timely reminder that our understanding of autism remains regrettably primitive. The theory originally espoused by Kanner ${ }^{3}$, that this distressing syndrome has its roots in the patient's human environment, apparently still has its adherents, despite increasing evidence of an organic aetiology $y^{4-8}$ with hereditary origins?.

Possibly the strongest recent endorsement of the organic view comes from the widely observed (L. Wing, personal communication) but inadequately documented fever effect ${ }^{10}$. When autistics have a moderate fever, they invariably display dramatically more normal behavioural patterns ${ }^{10}$, including a greater desire or ability to communicate. It is difficult to see how these observations could be explained on the basis of environmental factors.

The effect appears to reach a maximum for fevers in the range $1.5-2.5^{\circ} \mathrm{C}(\mathrm{T}$. Rørsvol, personal communication). It seems unlikely that such a modest rise could appreciably influence the rates of either the metabolic processes or the molecular diffusion involved in neural function. But temperature changes of as little as $1^{\circ} \mathrm{C}$ can markedly alter the fluidity of membranes ${ }^{11}$, such as those which form the synapses and the neurotransmitter-charged presynaptic vesicles.

An increase in the fluidity of these membranes would lower the vesiclesynapse fusion time, and thereby decrease the synaptic delay, which may well control what could be called the neural coherence length, which is a measure of the degree of inter-neurone cooperativity. Lower synaptic delays would increase this length, and one could speculate whether the autistic fever effect indicates that there is a connection between coherence in the behavioural sense and actual physical coherence at the neural level.

Equally intriguing is the possibility that autism stems from a neural lipid composition profile which departs from the ideal.

RODNEY M.J. COTTERILL Division of Molecular Biophysics, Technical University of Denmark, Building 307,

DK-2800 Lyngby,

Denmark

1. Bryant, P.E. Nature 305, 747 (1983)

2. Tinbergen, N. \& Tinbergen, E.A. Autistic Children: New Hope for a Cure (George Allen \& Unwin, London, 1983).

3. Kanner, L. Am. J. Psychiat. 103, 242-246 (1946); Nervous Child 2, 217-250 (1943)

4. Damasio, A.R. Arch. Neurol. 35, 777-786 (1978)

5. Piggott, L.R. J. Autism Dev. Disorders 9, 199-218 (1979)

6. Ciaranello,, R.D., Vanden Berg, S.R. \& Anders, T.F. J. Autism Dev. Disorders 12, 115-145 (1982).

7. Tanguay, P.E.\& Iidwards, R.M. J. Autism Dev. Disorders 12, 177-184 (1982).

8. Maurer, R.G. \& Damasio, A.R. J. Autism Dev. Disorders 12, 195-205 (1982).

9. Folstein, S. \& Rutter, M. Nature 265, 726-728 (1978)

10. Sullivan, R.C. J. Autism Dev. Disorders 10, 231-241 (1980).

11. Träuble, H., Tuebner, M., Woolley, P. \& Eibl, H. Biophys. Chem. 4, 319-337 (1976). 